\title{
Clinical Evolution Of Hypertension And Proteinuria In Patients Who Developed Preeclampsia
}

\author{
Z Joaquín, O Armando, M Hugo
}

\begin{abstract}
Citation
Z Joaquín, O Armando, M Hugo. Clinical Evolution Of Hypertension And Proteinuria In Patients Who Developed

Preeclampsia. The Internet Journal of Gynecology and Obstetrics. 2004 Volume 5 Number 1.
\end{abstract}

\begin{abstract}
Introduction: Preeclampsia-eclampsia has been one of the main cause of maternal morbidity-mortality in developing countries, affecting $10 \%$ of pregnancies. In Mexico, in the recent years it has been estimated at about 2 to 35 new cases per 100 pregnancies.
\end{abstract}

Objective: To report the evolution and severity of blood pressure and proteinuria; and their repercussion on renal function after delivery, in patients who developed preeclampsia.

Methods: It was a descriptive analysis of 24 preeclamptic women on clinical follow up until normalization of blood pressure.

Results: We observed lower serum albumin, higher severity of 24 hrs proteinuria level and longer duration of hypertension in those women who presented with the highest levels in diastolic blood pressure at the beginning and end of the study.

Name of the department and institution or hospital where the work was done: National Medical Center "20 de

Noviembre", ISSSTE, Mexico, City.

\section{INTRODUCTION}

Preeclampsia-eclampsia has one of the main cause of maternal morbidity and mortality in developing countries. It occurs in about $12-22 \%$ of pregnancies depending on the population and the definitions used, with unfavorable impact on maternal and perinatal health as it predisposes toward potentially lethal complications involving placental abruption, disseminated intravascular coagulation, hypertensive encephalopathy, intracranial hemorrhage, lung edema, hepatic failure, acute renal failure and cardiovascular collapse $\left({ }_{1}, 2,3\right)$. It is important to note that although mortality rates in developed countries are low, strategies for its prevention and treatment still received growing attention, due among other reasons, like cost-benefit considerations $\left(_{3}\right)$.

In Mexico, in the recent years it has been estimated at about 2 to 35 new cases per 100 pregnancies $\left(_{4}\right.$ ), and was the first leading cause of maternal death in the National Health Service, Mexico ${ }_{5}$ ). The medical literature review on the topic reveals an increased interest in the research directed to clarify the etiology and pathogenesis. There are many theories among which the major focus are the placenta as the cause of ischemic disturbances due to poor immunologic adaptation, genetic predisposition and secretion of vascular factors that cause placental endothelium morphological changes $\left({ }_{6}\right)$, the presence of von Willebrand factor, endothelin, prostacycline, thromboxane, and balance disturbance between the tissular plasminogen activator and inhibitor, favoring the increment of platelet aggregation and vasoconstriction $\left.{ }_{7}\right)$.

In preeclampsia, the principal renal histopathological alteration is glomerular endotheliosis, described as hypertrophy and edema of capillary cells by glomerular ischaemia, that causes decrease of blood flow and glomerular filtrate $\left({ }_{8}, 9\right)$.

Clinically hypertensive disease of the pregnancy has been classified by the World Health Organization, American College of Gynecology and Obstetrics, International Society for the Study of Hypertension, and by National Education Program Working Group on High Blood Pressure in Pregnancy, with this last one being the most accepted, and described as follows: $\left({ }_{10}, 11\right)$ : 
Preeclampsia:Systolic blood pressure $>140 \mathrm{~mm} \mathrm{Hg}$ or diastolic blood pressure $>90 \mathrm{~mm} \mathrm{Hg}$ on at least 2 occasions, 4 hours to 1 week apart, proteinuria (>300 mg in a 24-hour urine collection), and edema after the twentieth week of gestation.

Eclampsia:Generalized seizures in a preeclamptic pregnant woman.

Chronic arterial hypertension:Arterial hypertension before pregnancy.

Chronic arterial hypertension with preeclampsia: The combination of arterial hypertension and preeclampsia.

Gestational hypertension:Increment of arterial tension without being accompanied of proteinuria after the twentieth week of gestation. If it is resolved in the period of 12 weeks postpartum is called transitory gestational hypertension.

Efforts to recognize early this diagnosis in women with high risk to develop preeclampsia-eclampsia, is a concern for the obstetrician, because every woman in gravid state could suffer it, with higher incidence in those that have specific characteristics such as primiparity, multiple pregnancies, extreme ages and patients with diseases like diabetes mellitus and nephropathy as has been demonstrated in observational and epidemiological studies $\left({ }_{12}\right)$, but unfortunately the precipitating factors are still unknown. In spite of the advances in therapeutic outlines and its application, morbi-mortality rates have not been decreased $\left({ }_{13},{ }_{14}\right)$; with certainty later repercussions in medium and long time. Arterial hypertension is a risk factor for accelerated atheroesclerosis $\left({ }_{15}\right)$, as well as proteinuria as fact of renal damage; duration and intensity of these rebounds in renal function after childbirth in those women who suffered from preeclampsia-eclampsia.

Published studies of patients with severe preeclampsiaeclampsia point out the risk of recurrence in subsequent pregnancies, as well as the increment in the probability to present chronic arterial hypertension $\left(_{1}\right)$.

The aim of this study was to know the evolution and intensity of arterial pressure and proteinuria and its repercussion in renal function after childbirth, in patients who developed preeclampsia.

\section{MATERIAL AND METHODS}

It was carried out as a descriptive analysis of 24 pregnant women that presented preeclampsia according to the definition by the American College of Gynecology and Obstetrics. They were managed at the perinatology service of the National Medical Center "20 de Noviembre", ISSSTE, Mexico, City, and followed up in the Clinic of Hypertension, from January to August 2002.

Complete clinical history, and laboratory exams such as hematic biometry, glucose, creatinine, urea, electrolytes, hepatic function tests, serum albumin, 24 hrs creatinine clearance, and proteinuria in $24 \mathrm{hrs}$ were made, at the beginning and follow up of the study. Antihypertensive treatment on discharging from the perinatology service was implemented with metoprolol, captopril and nifedipine that were replaced by amlodipine and enalapril, when the former ones were in maximum doses. Doses of these drugs were modified depending on the clinical evolution. When the diastolic arterial pressure was of $90 \mathrm{~mm} \mathrm{Hg}$ or lower, determined in two or more occasions, treatment was suspended. The $24 \mathrm{hr}$ urine proteinuria was evaluated periodically until negative. Creatinine clearance was evaluated until arterial pressure control without drugs. Statistical analysis was performed using the SPSS10 program.

\section{RESULTS}

During this six month period we registered 24 patients, three of them were excluded because of antiphospholipid syndrome, hypothyroidism and chronic arterial hypertension. Cesarean section was performed on our 21 patients and their general data were:

- Mean age - 33 years (range 22- 42 years);

- Gravidity (G) - GI:8 (38.09\%), GII:7 (33.3\%), GIII:4 (19.04\%), GIV:1(4.76\%), GV:1 (4.76\%);

Weeks of gestation when preeclampsia diagnosis was made mean 29.4 weeks (range 21-38 weeks), 4 in the period of 20-24 weeks (19.04\%), 6 in 25-29 weeks (28.57\%), 9 in $30-34$ weeks (42.85\%), and 2 in 35-39 weeks (9.52\%) (Table 1). 


\section{Figure 1}

Table 1: Pregnancy information at the time of preeclampsia diagnosis

\begin{tabular}{|l|l|}
\hline Age (mean) & 33 years \\
\hline Number of pregnancies & \\
1 & $8(38.09 \%)$ \\
2 & $7(33.33 \%)$ \\
3 & $4(19.04 \%)$ \\
4 & $1(4.76 \%)$ \\
5 & $1(4.76 \%)$ \\
\hline Weeks of gestation & $4(19.04 \%)$ \\
$20-24$ & $6(28.57 \%)$ \\
$25-29$ & $9(42.85 \%)$ \\
$30-34$ & $2(9.52 \%)$ \\
$35-39$ & \\
\hline
\end{tabular}

Mean systolic blood pressure after patients underwent cesarean section was of $151.9 \mathrm{~mm} \mathrm{Hg}$ with diastolic blood pressure of $99.05 \mathrm{~mm} \mathrm{Hg}$. At the end of the follow up period the means were 116.71 and $75.95 \mathrm{~mm} \mathrm{Hg}$ (70-100) respectively, with a duration average of 79.5 days (20-224) (Table 2 and Fig 1). Besides, 14 patients required an average of 6.78 subsequent consults (with intervals of one month) to control arterial pressure with drugs and later on other 5 before discharge from study. 7 patients $(33.3 \%)$ were still on antihypertensive treatment at the end of our study, with a mean follow up of 95.14 days (28-160).

\section{Figure 2}

Table 2: Arterial blood pressure and laboratory findings

\begin{tabular}{|l|l|l|}
\hline Variable & Initial $^{*}$ & Final $^{*}$ \\
\hline $\begin{array}{l}\text { Systolic blood pressure } \\
\text { (mm Hg) }\end{array}$ & $151.9 \pm 24.82$ & $116.71 \pm 8.78$ \\
\hline $\begin{array}{l}\text { Diastolic blood pressure } \\
\text { (mm Hg) }\end{array}$ & $99.05 \pm 9.95$ & $75.95 \pm 8.89$ \\
\hline Proteinuria (gr/24 hr) & $2189.36 \pm 1652.94$ & 0 \\
\hline $\begin{array}{l}\text { Creatinine clearance } \\
\text { (ml/hr) }\end{array}$ & $97.95 \pm 30.72$ & $96.96 \pm 32.03$ \\
\hline Serum creatinine (mg/dl) & $0.84 \pm .30$ & $0.79 \pm 0.34$ \\
\hline Albumin (gr/dL) & $2.08 \pm 39$ & $2.78 \pm 0.59$ \\
\hline & \pm 1 standard deviation & \\
\hline
\end{tabular}

\pm 1 standard deviation

\section{Figure 3}

Figure 1: Evolution of systolic arterial pressure

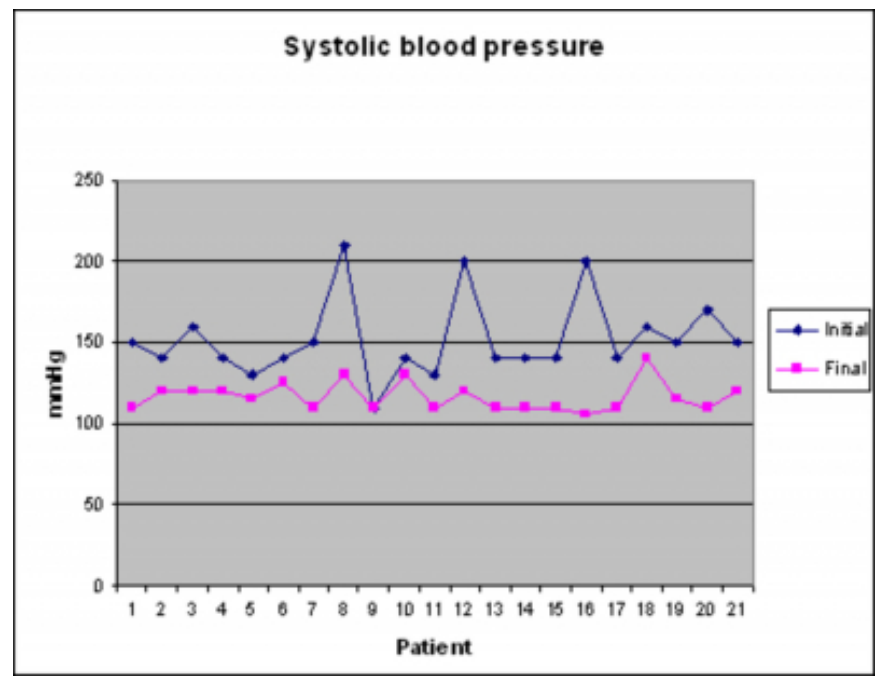

Mean creatinine clearance at delivery was of $96.9 \mathrm{ml} / \mathrm{hr}$ (37.96-146.7), and at the end of the study was of $93.8 \mathrm{ml} / \mathrm{hr}$ (30.73-164.7) (Table 2). One patient was included in protocol study of renal hypertension because she presented with more deterioration since delivery.

Initial mean proteinuria level was of $2.1 \mathrm{~g} / 24 \mathrm{hr}(0.5-6.1)$ and the last one before negative status was $1.64 \mathrm{~g} / 24 \mathrm{hr}(0.26$ - 8.75), with an average duration of 32.6 days (10-90). No patient presented with proteinuria at the end of the study (Table 2). Initial mean serum albumin was $2.08 \mathrm{mg} / \mathrm{dl}$ (1.5-2.9) and final was $2.78 \mathrm{gr} / \mathrm{dl}$ (1.6-4.6) with a mean duration of 32.6 days (10-90), coinciding its duration with the $24 \mathrm{hr}$ proteinuria (Table 2). Furthermore at the beginning of the study there was no significative statistical relationship between diastolic pressure and creatinine clearance but at the end, increment of diastolic pressure correlated with diminished albumin (Pearson correlation of -0.386).

Intensity of $24 \mathrm{hr}$ proteinuria was higher in those women that also had higher diastolic blood pressure at the beginning and end. In addition we found a significant negative correlation between creatinine clearance and serum creatinine (Pearson of -0.474). Also there were negative correlations between systolic blood pressure with serum creatinine and albumin (Pearson of -0.207 and -0.358 respectively).

Duration of arterial hypertension was associated with the higher intensity of diastolic blood pressure at the beginning and end. Also, lower gestation showed higher increment in final arterial blood pressure $(\mathrm{p}<0.01)$, higher intensity of final $24 \mathrm{hr}$ proteinuria $(\mathrm{p}<0.05)$ and longer duration of hypertension $(\mathrm{p}<0.01)$. Finally, with younger age at 
preeclampsia diagnosis, longer duration of hypertension was observed $(\mathrm{p}<0.01)$.

\section{DISCUSSION}

In Mexico as in other countries, preeclampsia is more frequent in primiparous women, $52 \%$ of all cases, and they also have twice the risk of suffering from it in a subsequent pregnancy $\left.{ }_{9}\right)$. Preeclampsia is more frequent in patients younger than 21 years of age and in older than 35 . In our study the mean age was of 33 years old.

The mean week of gestation when diagnosis was made was of 29.4 weeks, higher than 25 weeks, reported by Siba $\left(_{1}\right)$.

However, we can appreciate that in the group of patients that reached blood pressure control, creatinine clearance and albumin were higher than in the group of no controlled women; in addition, serum creatinine was lower in the first one (Table 3 ). In any case there was no significative statistical difference.

\section{Figure 4}

Table 3: Final values in controlled and not controlled patients

\begin{tabular}{|l|l|l|}
\hline Variable & Controlled $(\mathbf{N}=14)$ & Not controlled $(\mathbf{N}=7)$ \\
\hline $\begin{array}{l}\text { Systolic blood pressure } \\
\text { (mmHg) }\end{array}$ & 114 & 122.1 \\
\hline $\begin{array}{l}\text { Diastolic blood pressure } \\
\text { (mmHg) }\end{array}$ & 73.21 & 81.43 \\
\hline $\begin{array}{l}\text { Creatinine clearance } \\
\text { (m//hr) }\end{array}$ & 104.7 & 81.53 \\
\hline Serum creatinine (mg/di) & 0.72 & 0.93 \\
\hline Albumin (gr/dL) & 2.91 & 2.54 \\
\hline
\end{tabular}

Early beginning of preeclampsia in primigravida is an important antecedent that is taken into account for maternal and infantile long term morbi-mortality prognosis, because of the repercussion in the severity of this disease $\left(_{1}\right.$ ), that we have verified in our study. Nevertheless previous studies does not consider the increase in arterial blood pressure and proteinuria, that we suggest to be related with primiparity and early beginning of preeclampsia, because of longer duration of arterial hypertension after childbirth.

In our study, after childbirth, mean duration of hypertension was of 79.5 days, higher than that reported by Ferrazzani et al. $\left(_{16}\right)$ of 16 days, but their patients had younger gestational age and less proteinuria. Unless, they did not correlate changes in arterial blood pressure which is critical to evaluate evolution and limit renal damage.

After pregnancy is finished, proteinuria commonly disappears within 3 to 8 weeks, but occasionally persists for months $\left({ }_{17}\right)$. Literature reports that in preeclampsia, both glomerular filtration rate and renal plasma flow decrease by
$30 \%$ to $40 \%$ compared with normal pregnancy of the same duration $\left({ }_{18}, 19\right)$. In our work, renal function at the beginning of the study was of $96.9 \mathrm{ml} / \mathrm{min}$ which decreased to 93.8 $\mathrm{ml} / \mathrm{min}$ at the end, detecting higher renal impairment related to higher diastolic blood pressure and proteinuria, in primiparous women with early beginning of preeclampsia, in fact, one patient did not return to normal creatinine clearance that could be a rare case of prolonged renal hypoperfusion with resulting "acute tubular necrosis" $\left({ }_{17}\right)$. Anyway, if we analyze by comparing the clinical and laboratory findings of the seven uncontrolled women at the end of the study with the 14 controlled we didn't find significative statistical difference (the lowest $\mathrm{p}$ was of 0.09 with systolic as well as diastolic blood pressure comparing both groups) using nonparametric tests due to the low number of preeclamptic women.

The importance of following up primigravids with early beginning of preeclampsia, high diastolic blood pressure and proteinuria, after childbirth, is crucial for prognosis, repercussion in antihypertensive treatment duration and because this last factor implication towards renal function. Also, this knowledge can help in planning new pregnancies, since repetition of preeclampsia has been seen in the subsequent ones, with the risk of permanent arterial hypertension. Previous works suggest the hypothesis of positive correlation between creatinine clearance and endotheline, as has been shown by endothelium cell damage $\left({ }_{1}, 16\right)$, proving that patients with severe preeclampsia have high incidence of chronic hypertension in a range from 1 to 11 years after delivery, and thus it is important to have clinical follow up for a longer time.

Based on the results of our study we conclude the following

1. Preeclampsia was more common in primiparous young women.

2. The severity of increment in levels of diastolic blood pressure was related to the decrease in final creatinine clearnance.

3. Decrease in serum albumin, higher severity of 24 hrs proteinuria and longer duration of hypertension was observed in those women who presented with higher diastolic blood pressure at the beginning and end of the study.

4. In those women with less pregnancies, it was observed that there were longer duration of 
hypertension and higher intensity of proteinuria.

5. At earlier age of preeclampsia diagnosis, higher severity of hypertension was observed.

Vigilance of arterial hypertension and renal function as well as their early treatment can avoid the progression to renal damage and subsequent chronic arterial hypertension in preeclamptic women.

Because dysregulation of the maternal immune response to pregnancy may play an important role in the cause of complicated pregnancies $\left({ }_{20}\right)$, it is very important for future basic and clinical research to look for medical alternatives to prevent this disease.

\section{CORRESPONDENCE TO}

Hugo Mendieta Zerón, MD. University of Santiago de Composela School of Medicine Phisiology Department Rua San Francisco s/n 15782 Tel: 981-582658 ext. 12260 E. mail: mezh_74@yahoo.com

\section{References}

1. Sibai BM, Mercer B, Sarinoglu C. Severe preeclampsia in the second trimester: recurrence risk and long-term prognosis. Am J Obset Gynecol 1991;165(5 Pt

1):1408-1412.

2. Barton JR, O’Brien JM, Bergauer NK, Jacques DL, Sibai BM. Mild gestational hypertension remote from term: progression and outcome. Am J Obstet Gynecol 2001;184(5):979-983.

3. Sibai BM, Sarinoglu C, Mercer BM. Eclampsia. VII. Pregnancy outcome after eclampsia and long-term prognosis. Am J Obstet Gynecol 1992;166(6 Pt 1):1757-1761.

4. Mar-Ibañez A. Epidemiología de la preeclampsiaeclampsia en México. Epidemiología 2001; 18(16):1-2.

5. Velasco-Murillo V, Pozos CJL, Cardona PJA. Prevención y tratamiento de la preeclampsia-preeclampsia. De la teoría a la práctica. Rev Med IMSS 2000; 38(2):139-147.

6. Chaiworapongsa T, Romero R, Espinoza J, Bujold E, Mee Kim Y, Goncxalves LF, et al. Evidence supporting a role for blockade of the vascular endothelial growth factor system in the pathophysiology of preeclampsia. Am J Obstet Gyneco 2004;190:1541-1550.

7. Van Beek E, Peeters L. Pathogenesis of preeclampsia: a comprehensive model. Am J Obset Gynecol 1998; 53(4):233-239.

8. Paller MS. Disease of the month. hypertension in pregnancy. J Am Soc Nef 1998; 9(2):314-321.

9. Gaber L, Spargo BH, Lindheimer. Renal pathology in preeclampsia. Clin Obstet Gynecol 1994;8:443-468. 10. Report of the national high blood pressure education program group on high blood pressure in pregnancy. Am J Obstet Gynecol 2000;183:S1-S22.

11. Garovic VD. Hypertension in pregnancy: diagnosis and treatment. Mayo Clinic Proc 2000; 75(10):1071-1076.

12. Lara-Gonzalez AL, Romero-Arauz JF, et at. Factores de riesgo para preeclampsia. Análisis multivariado. Ginecol Obste Mex 2000;68(8):357-362.

13. Romero-Arauz JF, Lara-Gonzalez AL, Izquierdo-Puente C. Manejo conservador en preeclampsia severa. Ginecol Obstet Mex 2000;68 (2):357-362.

14. Magee LA, Ornstein MP, von Dadelszen P. Fortnightly review: management of hypertension in pregnancy. BMJ. 1999;318(7194):1332-1336.

15. Perlff D. Hypertension and pregnancy-related hypertension. Cardiol Clin 1998; 16(1):79-101.

16. Ferrazzani S, De Carolis S, Pomini F, Testa AC, Mastromarino $\mathrm{C}$, Caruso A. The duration of hypertension in the puerperium of preeclamptic women: relation with renal impairment and week of delivery. Am J Obstet Gynecol 1994;171(2):506-512.

17. Karumanchi SA, Maynard SE, Stillman IE, Epstein FH, Sukhatme VP. Preeclampsia: A renal perspective. Kidney Int 2005;67:2101:2113.

18. Lafayette RA, Druzin M, Sibley R, Derby G, Malik T, Huie $\mathrm{P}$, et al. Nature of glomerular dysfunction in preeclampsia. Kidney Int 1998;54:1240-1249.

19. Moran P, Baylis PH, Lindheimer MD, Davison JM. Glomerular ultrafiltration in normal and preeclamptic pregnancy. J Am Soc Nephrol 2003;14:648-652.

20. Steinborn A, Rebmann V, Scharf A, Sohn C, GrosseWilde H. Soluble HLA-DR levels in the maternal circulation of normal and pathologic pregnancy. Am J Obstet Gynecol 2003;188:473-479 


\section{Author Information}

Zúñiga Madrazo Joaquín, M.D.

Hypertension Clinic, National Medical Center "20 de Noviembre", ISSSTE

Orbe Cabrera Carlos Armando, M.D.

Resident of Cardiology, National Medical Center "20 de Noviembre", ISSSTE

Mendieta Zerón Hugo, M.D.

Internal Medicine, Sanatorio "Toluca" 